\title{
Simultaneous spectrophotometric determination of nitroanilines using genetic-algorithm-based wavelength selection in principal component-artificial neural network
}

\author{
Mohammad Goodarzi ${ }^{1,2}$, Ashok Kumar Malik ${ }^{3}$ and Nasser Goudarzi ${ }^{4 *}$ \\ ${ }^{1}$ Young Researches Club, Azad University, Arak, Iran. \\ ${ }^{2}$ Department of Chemistry, Faculty of Science, Azad University of Arak, Arak, Iran. \\ ${ }^{3}$ Department of Chemistry, Punjabi University, Patiala-147 002, Punjab, India \\ ${ }^{4}$ Faculty of Chemistry, Shahrood University of Technology, P. O. Box 316, Shahrood, Iran.
}

Accepted 5 December, 2012

\begin{abstract}
Ternary mixtures of nitroaniline isomers have been simultaneously determined in synthetic and real matrix by application of genetic algorithm principal component artificial neural network model. All effective factors on the sensitivity were optimized. Also, the linear dynamic range for determination of nitroaniline isomers was found. The simultaneous determination of nitroaniline mixtures by using spectrophotometric methods due to spectral interferences is a difficult problem. A genetic algorithm is a suitable method for selecting wavelength for principal component-artificial neural network (PC-ANN) calibration of mixtures with almost identical spectra without loss prediction capacity. The experimental calibration matrix was designed by measuring the absorbance over the range of 200 to $500 \mathrm{~nm}$ for 21 samples of 1.0 to $17.0,1.0$ to 15.0 and 1.0 to $18.0 \mu \mathrm{g} / \mathrm{ml}$ of $m$-nitroaniline, $o$-nitroaniline and $p$ nitroaniline, respectively. The root mean square error of prediction for $m$-nitroaniline, $o$-nitroaniline and $p$-nitroaniline were $0.7848,0.2864$ and 0.1851 , respectively. The proposed method was successfully applied for the determination of $m$-nitroaniline, $o$-nitroaniline and $p$-nitroaniline in synthetic and water samples.
\end{abstract}

Key words: Nitroaniline isomers, genetic algorithm, principal component, artificial neural network.

\section{INTRODUCTION}

Nitroanilines are important pollutants in water because of their wide use in many industrial processes such as the manufacture of pharmaceuticals, dyes and synthetically colors. Furthermore, they are of great environmental concern because of their high toxicity to living things (Gurten et al., 2006). Actually, they can be released into the environment either directly as industry waste or indirectly as breakdown products of herbicides and pesticides. Due to their solubility in water, anilines can

\footnotetext{
*Corresponding author. E-mail: goudarzi@shahroodut.ac.ir or goudarzi10@gmail.com. Tel: +982733335441. Fax: +982733335441.
}

readily permeate through soil and contaminate ground water. They can be taken up by humans via the skin, the respiratory tract and the gastrointestinal tract. Because of their toxicity, bioaccumulation and vast scale distribution in the ecological environment, their separation and determination have become one of the important studies of environmental analysis. A variety of analytical methods have been reported for the determination of selected anilines. Such analytical techniques have been included: gas chromatography (Farroha and Emeish, 1975; LopezAviia and Northcutt, 1981), pulse polarography (Wolff and Nürnberg, 1966), liquid chromatography (Scher and Adamo, 1993), voltammetry (Au Kuzmina et al., 2003; Grabaric et al., 1997; Isaeva et al., 1991; Faller et al., 1996) and spectrophotometry (Ai-Ghabsha et al., 1976; 
Table 1. Parameters of the genetic algorithms.

Population size: 30 chromosomes

On average, five variables per chromosome in the original population

Response: cross-validated percentage explained variance (five deletion groups; the number of components is determined by cross validation).

Maximum number of variables selected in the same chromosome: 30

Probability of mutation: $1 \%$

Maximum number of components: the optimal number of components determined by cross-validation on the model containing all the variables (not higher than 15).

Number of runs: 100

Backward elimination after every 100th evaluation and at the end (if the number of evaluations is not a multiple of 100).

Window size for smoothing: 3

Revanasiddappa et al., 2001; Ghasemi and Niazi, 2007; Rahim et al., 1987). A drawback of the techniques of feature selection when applied to spectral data is that usually the selected features (wavelengths) are scattered throughout the spectrum. It has already been shown that genetic algorithms (GAs) (Arcos et al., 1997; Depczynski et al., 2000; Lucasius and Kateman, 1993; Hibbert, 1993) can be successfully used as a feature selection technique (Leardi et al., 1992, 1998, 2002; Leardi, 1994, 1996, 2000, 2007). Leardi and Gonzalez (1998) demonstrated that GAs, after suitable modifications, produce more interpretable results, since the selected wavelengths are less dispersed than with other methods. The algorithm used in this paper is an evolution of the algorithm described in Leardi et al. (1998), whose parameters are reported in Table 1.

Simultaneous determination of components in a multicomponent drug formulation could be a difficult task, especially when characteristics of these components from analytical point resemble closely in addition to the presence of other pharmaceutical excipients. In recent past, multivariate chemometric methods for analysis of multicomponent systems have been reported in international journals mostly due to the advent of fast and affordable computers and rapid scanning spectrophotometers controlled by computer software. Artificial neural networks (ANNs) are a data processing system consisting of a large number of simple, highly intercomnected processing elements inspired by the biological system and designed to simulate neurological processing ability of human brain. Theoretical background information on ANNs can be found elsewhere (Rumelhart and McClelland, 1986; Fausett, 1994; Schalkoff, 1997).
Applications of ANNs in the field of chemistry and pharmacy have been reviewed (Zupan et al., 1997; Bourquin et al., 1997; Despagne and Massart, 1998; Salari et al., 2005; Zupan and Gasteiger, 1999; Pan et al., 2007; Zhang et al., 2005; Zhang, 2007; García-Reiriz et al., 2007; Tang et al., 2006; Absalan and Soleimani, 2004; Balamurugan et al., 2003).

Computationally, ANN is an approach for handling multivariate and multi-response data and hence suitable for modeling, that is, a search for an analytical function that will give a specified n-variable output for any mvariable input (Zupan and Gasteiger, 1999). Unlike standard modeling techniques where the mathematical function is required to be known in advance, ANN models do not require the knowledge of the mathematical function in advance, and are called 'soft models', that is, the models are able to represent the experimental behavior of the system when the exact description is missing or too complex. ANNs adapt to any relation between input and output data on the basis of their supervised training. The characteristics that make ANN systems different from traditional computing are: learning by example, distributed associative memory, fault tolerance and pattern recognition (García-Reiriz et al., 2007; Tang et al., 2006; Absalan and Soleimani, 2004). The flexibility of ANNs and their ability to maintain their performance even in the presence of significant amounts of noise in the input data are highly desirable (Fausett, 1994; Despagne and Massart, 1998). Since perfectly linear and noise free data sets are seldom available in practice, thus making it suitable for multivariate calibration modeling. There are reports on the application of ANNs for mixture analysis (Absalan and Soleimani, 2004; Balamurugan et 
al., 2003; Sathyanarayana et al., 2004; Yin et al., 2001; $\mathrm{Ni}$ et al., 2000).

Though, most of them employ separate networks for estimation of each component and calibration involving synthetic binary mixtures for calibration. The current research work evaluates the performance characteristics of principal component-artificial neural network (PC-ANN) model trained by Levenberg-Marquardt algorithm (Hagan and Menhaj, 1994). The use of computed spectral datasets has been demonstrated of using spectra of synthetic mixtures for the calibration models. A method for routine pharmaceutical quality control of this tablet dosage form by multivariate calibration based on soft modeling using principal component based backpropagation neural network has been presented. This method was used for simultaneous spectrophotometric determination of nitroanilines in different samples and results show the applicability of this procedure for analysis of real samples.

\section{THEORY}

\section{The statistical package used for data analysis principal component analysis}

Principal component analysis (PCA) is a multivariate procedure that reduces dimensionality of data space while retaining as much information that is possible. It can be viewed as rotation of the existing axes of rotary positioning (RP) to a new position in it, such that maximum variability of data space is projected onto the axes (Hagan, 1966; Berzas et al., 1997; Marbach and Heise, 1990; Goodarzi et al., 2007; Jalali-Heravi et al., 2004; Kalivas, 2001). The first principal component (PC) is the combination of variables that explains the greatest amount of variations. The second principal component defines the next largest amount of variation and is independent to the first principal component. There can be as many possible principal components as there are variables. A particular direction that defines a linear latent variable in RP is described by a vector $\mathrm{b}\left(b_{1}, b_{2}, \ldots, b_{p}\right)$ which is usually scaled to length one. The value of the corresponding latent variable $u$ for an object, $\mathrm{x}\left(x_{1}, x_{2}, \ldots\right.$, $\left.x_{p}\right)$ is obtained by projecting the object points onto a straight line which is defined by the direction $b$. Mathematically, this is a linear combination of the features $x_{j}$ of the object and the vector component $b_{i}$.

$$
\mathbf{u}=\mathbf{b}^{\mathrm{T}} \mathbf{x} \sum_{i, j=1}^{i, j=p} b_{i} x_{j}
$$

The vector components $b_{i}$ and $x_{i}$ are, respectively called loadings and scores are given by the eigenvectors of the covariance matrix.

\section{Genetic algorithm}

A detailed explanation of the GAs can be found in previous researches (Hibbert, 1993; Leardi et al., 1992, 1998; Leardi, 1994, 1996, 2000, 2007), and a brief introduction to the method will be given subsequently. GA is a simulated method based on ideas from Darwin's theory of natural selection and evolution (the struggle for life). In GA for variable selection, an individual (or chromosome), that is, solution, represents a set of variables; they are the following basic steps in algorithms: (1) a chromosome is represented by a binary bit string and an initial population of chromosomes is created in a random way; (2) a value for the fitness function of each chromosome is evaluated; (3) according to the values of the fitness function, the chromosomes of the next generation are reproduced by selection, crossover and mutation operations. In this paper, the genetic algorithms follow Leardi's method (Leardi et al., 1998) (Table 1).

\section{Artificial neural networks (ANNs)}

ANN is a computer based system derived from the simplified concept of the brain in which a number of nodes, called processing elements or neurons, are intercomnected in a netlike structure. The ANN characteristics have been found to be nonlinear making them suitable for data processing in which the relationship between cause and results cannot be linearly defined. Three components constitute an ANN: the processing elements, the topology of connection between the nodes and the learning rules. The PCA selected by loading plot were processed by ANN which was trained with the back-propagation of errors learning algorithm. Its basic theory and application to chemical problems can be found in the literature (Wythoff, 1993; Zupan and Gasteiger, 1991). The structure of the network comprised of three node layers: an input, a hidden and an output layer, represented by $\mathrm{i}$, $\mathrm{h}$ and $\mathrm{o}$, where they, respectively, indicate the number of nodes in the input layer, hidden layer and output layer. The absorbance data versus the time were centered and normalized as the input for ANN. The input nodes transferred the weighted input signals to the nodes in the hidden layer, and the same as the hidden nodes for the output layer (Table 2).

\section{EXPERIMENTAL}

\section{Reagents and standard solutions}

All the chemicals used were of analytical reagent grade, sub-boiling distilled water was used throughout. Stock solutions of nitroaniline isomers were purchased from Fluka Company. Standards of working solution were made by appropriate dilution daily as required. A universal buffer solution ( $\mathrm{pH} 7.0)$ was prepared by Lurie (1978). 
Table 2. Architecture of the ANN models and their specifications.

\begin{tabular}{lc}
\hline No. of nodes in the input layer & $3+1^{\mathrm{a}}$ \\
No. of nodes in the hidden layer & 3 \\
No. of nodes in the output layer & 3 \\
Performance ratio & 0.5 \\
No. of iterations & 10 \\
Transfer function & $x_{K+1}=x_{K}-\left[J^{T} J+\mu I\right]^{-1} J^{T} e$ \\
\hline
\end{tabular}

${ }^{a}$ bias.

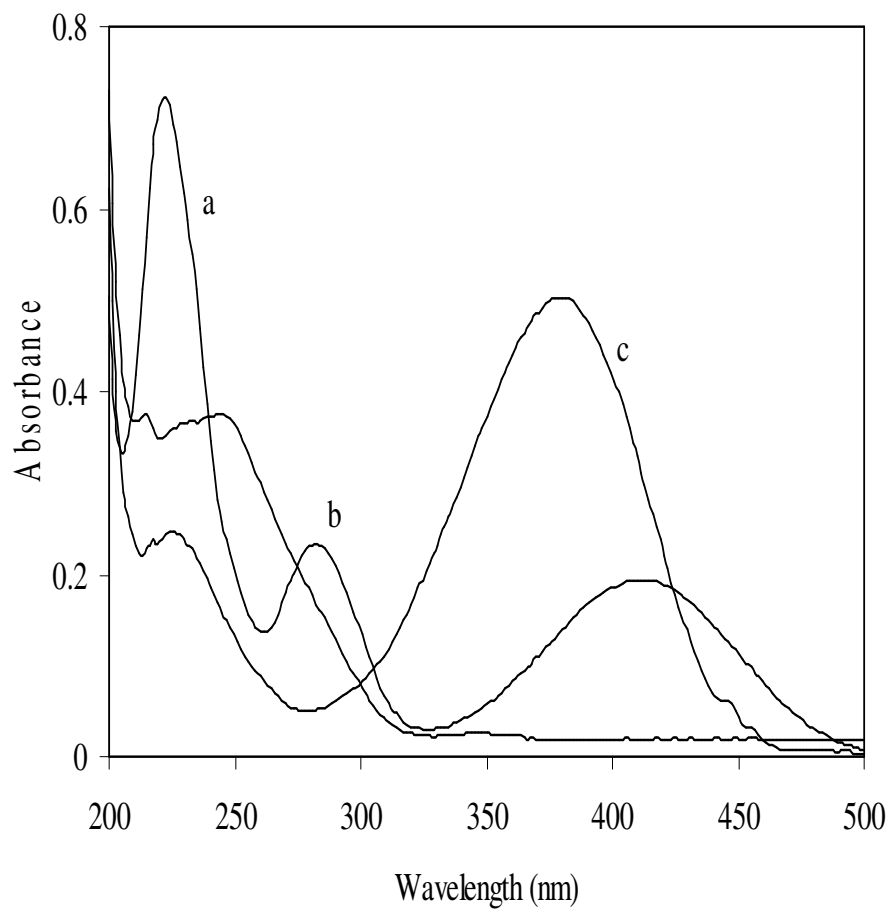

Figure 1. Typical spectrum of the individual nitroaniline isomers (concentration of (a) m-nitroanaline $9 \mu \mathrm{g} / \mathrm{ml}$, (b) o-nitroanaline 8 $\mu \mathrm{g} / \mathrm{ml}$ and (c) p-nitroanaline $6 \mu \mathrm{g} / \mathrm{ml}$ ) at $\mathrm{pH} 7.0$.

\section{Instrumentation and software}

A Scinco (SUV-2120) spectrophotometer controlled by a HewlettPackard computer and equipped with a $1 \mathrm{~cm}$ pathlength quartz cell was used for UV-vis spectra acquisition. A Metrohm $692 \mathrm{pH}$-meter furnished with a combined glass-saturated calomel electrode was calibrated with at least two buffer solutions at $\mathrm{pH} 3.00$ and 9.00. The backpropagation neural network algorithm having three layers was used in Matlab (version 6.5, MathWork Inc.) using NNet Toolbox. It is worth mentioning that GA variable selection and PCA modeling were also written in the same software.

\section{Linear calibration range}

Individual calibration curves were constructed with several points as absorbance versus $m$-nitroaniline, $o$-nitroaniline and $p$-nitroaniline concentrations. For constructing the individual calibration lines, the absorbances were measured at 251, 225 and $381 \mathrm{~nm}$ against a blank for $m$-nitroaniline, o-nitroaniline and $p$-nitroaniline, respectively. The linear regression equation for the calibration graph for $m$-nitroaniline for the concentration range of 1.0 to 17.0 $\mu \mathrm{g} / \mathrm{ml}$ was $A=0.0726 C_{m \text {-nitroaniline }}+0.0451\left(R^{2}=0.996\right)$ and for 0 nitroaniline for the concentration range of 1.0 to $15.0 \mu \mathrm{g} / \mathrm{m}$ was $A=$ $0.0775 C_{o \text {-nitroaniline }}+0.0772\left(R^{2}=0.999\right)$ and for $p$-nitroaniline for the concentration range of 1.0 to $18.0 \mu \mathrm{g} / \mathrm{m}$ was $\mathrm{A}=0.0769 \mathrm{C}_{p \text {-nitroaniline }}+$ $0.0206\left(R^{2}=0.9973\right)$. The limits of detection were $0.04,0.07$ and $0.05 \mu \mathrm{g} / \mathrm{m}$ for $m$-nitroaniline, o-nitroaniline and $p$-nitroaniline, respectively, and these were calculated according to calibration line characteristics.

\section{Procedure of standard calibration set}

The concentrations of $m$-nitroaniline, $o$-nitroaniline and $p$ nitroaniline varied between 1.0 and 17.0, 1.0 and 15.0 and 1.0 and $18.0 \mu \mathrm{g} / \mathrm{m}$, respectively. The mixed standard solutions were placed in a $10 \mathrm{ml}$ volumetric flask and completed to the final volume with deionized water (final $\mathrm{pH}$ 7.0). The absorption spectra were recorded between 200 and $500 \mathrm{~nm}$ against a blank of universal buffer. The spectral region between 200 and $500 \mathrm{~nm}$, which implies working with 301 experimental points per spectra (as the spectra are digitized each $1.0 \mathrm{~nm}$ ), was selected for analysis, because this is the zone with the maximum spectral information from the mixture components of interest. All absorption data are preprocessed by standard mean centring and scaling.

\section{RESULTS AND DISCUSSION}

\section{Selection of the optimum chemical conditions}

Figure 1 shows the absorption spectra in aqueous solution of individual nitroaniline isomers at $\mathrm{pH}$ 7.0. With the aim of investigation, the possibility of determining nitroaniline isomers in mixtures, the optimum working conditions were studied under the conditions previously established for each nitroaniline isomers. A universal buffer solution of $\mathrm{pH} 7.0$ was selected. In order to select the optimum $\mathrm{pH}$ value at which the minimum overlap occurs, influences of the $\mathrm{pH}$ of the medium on the absorption spectra of nitroaniline isomers were studied over the $\mathrm{pH}$ range 4.0 to 10.0 . Individual calibration curves were constructed with several points, as absorbance versus nitroaniline isomers concentration in the range 1.0 to $17.0,1.0$ to 15.0 and 1.0 to $18.0 \mu \mathrm{g} / \mathrm{ml}$ for $m$ nitroaniline, $o$-nitroaniline and $p$-nitroaniline, respectively. The wavelengths used to generated calibration curves 
Table 3. Concentration data of the different mixtures used in the calibration set for determination of nitroaniline isomers.

\begin{tabular}{cccc}
\hline Sample & Meta & Ortho & Para \\
\hline Training & & & \\
1 & 1 & 1 & 18 \\
2 & 17 & 1 & 4.4 \\
3 & 9 & 9.4 & 1 \\
4 & 1 & 9.4 & 7.8 \\
5 & 9 & 3.8 & 7.8 \\
6 & 5 & 9.4 & 4.4 \\
7 & 10.5 & 3 & 7.2 \\
8 & 9 & 1 & 11.2 \\
9 & 17 & 3.8 & 1 \\
10 & 1 & 15 & 1 \\
11 & 1 & 3.8 & 14.6 \\
12 & 5 & 6.6 & 7.8 \\
13 & 16 & 1.2 & 4 \\
14 & 7 & 5 & 8.5 \\
& & & \\
Validation & & 1 & 7.8 \\
15 & 13 & 6.6 & 1 \\
16 & 13 & 12.2 & 4.4 \\
17 & 1 & 3.8 & 11.2 \\
18 & 5 & 6.6 & 4.4 \\
19 & 9 & 6.8 & 1.2 \\
20 & 12 & 11 & 4 \\
21 & 2.3 & &
\end{tabular}

Unit: $\mu \mathrm{g} / \mathrm{ml}$.

Table 4. Added and found results of synthetic mixtures of nitroaniline isomers by GA-PC-ANN method ( $\mu \mathrm{g} / \mathrm{ml})$.

\begin{tabular}{cccccccccc}
\hline \multirow{2}{*}{ Sample } & \multicolumn{3}{c}{ Added } & \multicolumn{3}{c}{ Found } & \multicolumn{3}{c}{ Recovery (\%) and (RSD) } \\
\cline { 2 - 10 } & Meta & Ortho & Para & Meta & Ortho & Para & Meta & Ortho & Para \\
\hline 1 & 5.00 & 1.00 & 14.6 & 6.81 & 0.90 & 15.0 & $136.1(0.05)$ & $89.9(1.02)$ & $102.9(0.7)$ \\
2 & 5.00 & 12.2 & 1.00 & 4.62 & 11.97 & 0.98 & $92.38(0.08)$ & $98.08(0.04)$ & $98.0(0.15)$ \\
3 & 1.00 & 6.60 & 11.2 & 0.98 & 7.20 & 11.2 & $98.75(0.02)$ & $109.4(1.01)$ & $99.7(0.09)$ \\
4 & 13.0 & 3.80 & 4.40 & 12.5 & 3.90 & 4.50 & $96.12(1.03)$ & $105.2(1.75)$ & $102.0(1.23)$ \\
5 & 4.00 & 1.50 & 15.0 & 6.81 & 1.50 & 15.0 & $100.0(0.03)$ & $100.0(0.07)$ & $100.0(0.03)$ \\
6 & 9.00 & 6.00 & 4.50 & 9.14 & 6.01 & 4.48 & $101.5(0.07)$ & $100.2(0.3)$ & $99.6(0.60)$ \\
\hline
\end{tabular}

Unit: $\mu \mathrm{g} / \mathrm{ml}$

were 251, 225 and $381 \mathrm{~nm}$ for $m$-nitroaniline, onitroaniline and $p$-nitroaniline, respectively.

\section{Calibration and validation}

Calibration matrix of synthetic mixtures of nitroaniline isomers by genetic algorithm-principal componentartificial neural network (GA-PC-ANN) method was designed. In Table 3, the compositions of the ternary mixtures used in the calibration matrices are summarized. For prediction set, six mixtures were prepared (Table 4). To ensure that the prediction and real samples are in the subspace of training set, the score plot of first principal component versus second was sketched and all the samples are spanned with the training set scores. 
Table 5. GA-PC-ANN results applied on the real matrix samples $(\mu \mathrm{g} / \mathrm{ml})$.

\begin{tabular}{|c|c|c|c|c|c|c|c|c|c|c|c|c|}
\hline \multirow{2}{*}{$\begin{array}{l}\text { Type } \\
\text { of } \\
\text { water }\end{array}$} & \multicolumn{4}{|c|}{$m$-nitroaniline } & \multicolumn{4}{|c|}{ o-nitroaniline } & \multicolumn{4}{|c|}{$p$-nitroaniline } \\
\hline & Added & Found & $S D^{b}$ & $\begin{array}{c}\text { Recovery } \\
(\%)\end{array}$ & Added & Found $^{a}$ & $S D^{b}$ & $\begin{array}{c}\text { Recovery } \\
(\%)\end{array}$ & $\begin{array}{c}\text { Adde } \\
\text { d }\end{array}$ & Found & $S D^{b}$ & $\begin{array}{c}\text { Recovery } \\
(\%)\end{array}$ \\
\hline River & 4.0 & 3.9 & 0.75 & 97.5 & 1.5 & 1.46 & 0.4 & 97.3 & 1.0 & 1.1 & 0.35 & 110 \\
\hline Waste & 6.0 & 5.86 & 2.31 & 97.7 & 6.0 & 5.9 & $\begin{array}{c}1.2 \\
1\end{array}$ & 98.3 & 7.0 & 7.01 & 0.61 & 100.1 \\
\hline Tap & 5.5 & 5.45 & 1.63 & 99.1 & 8.0 & 7.87 & $\begin{array}{c}0.9 \\
8\end{array}$ & 98.4 & 9.8 & 9.6 & 1.20 & 97.9 \\
\hline Tap & 12 & 12.3 & 2.15 & 102.5 & 14 & 14.7 & 1.4 & 105 & 5.5 & 5.49 & 2.1 & 99.8 \\
\hline
\end{tabular}

${ }^{a}$ Mean of three measurements. ${ }^{b}$ Relative standard deviation for $n=3$.

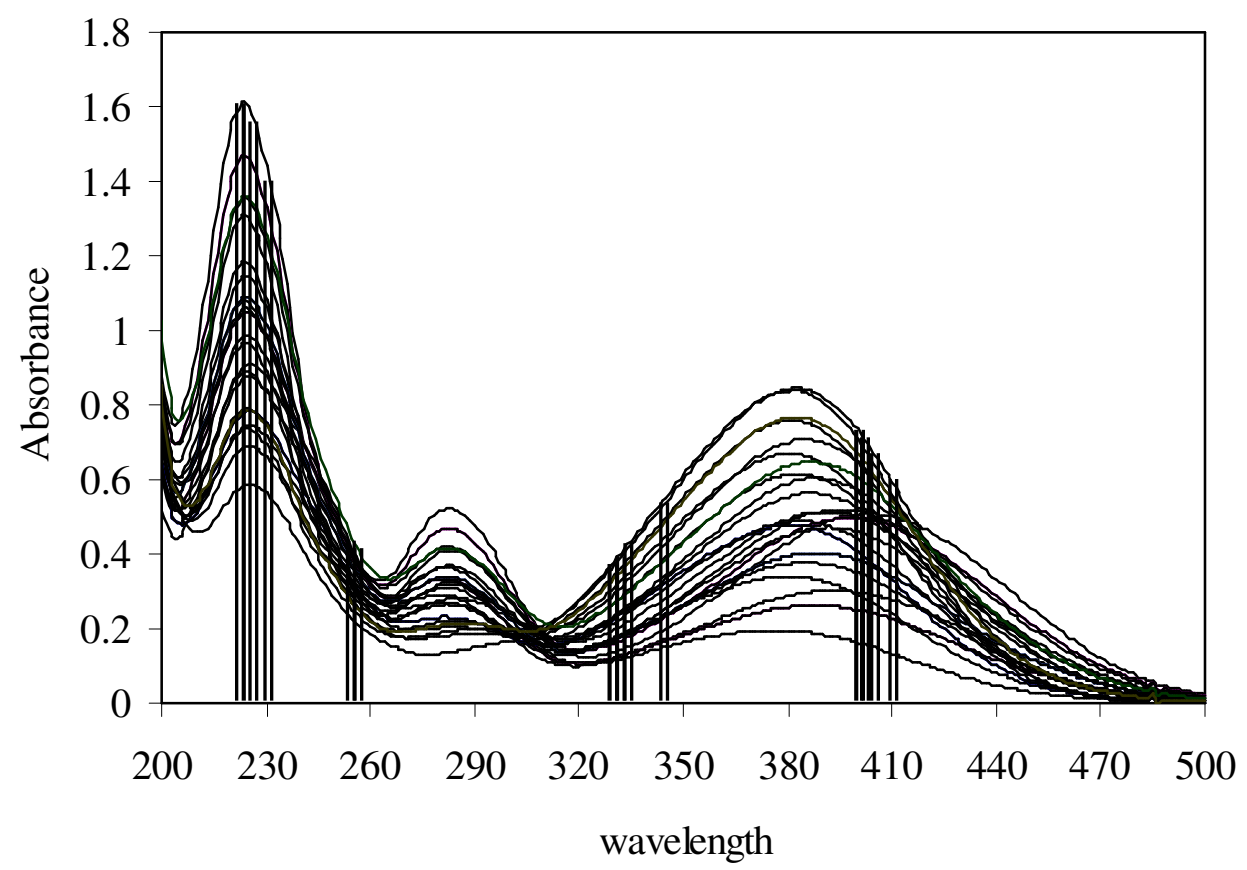

Figure 2. Absorbance spectra for calibration set and wavelength selected for nitroaniline isomers.

\section{Prediction set and analysis of real samples}

For prediction set, 6 mixtures were prepared which did not include previous set and were used as an independent test (Table 4). The real samples in this study were collected in different waters (Table 5). The range concentrations were added to be 1.0 to $13.0,1.0$ to 12.0 , and 1.0 to $15.0 \mu \mathrm{g} / \mathrm{ml}$ for $m$-nitroaniline, o-nitroaniline and $p$-nitroaniline, respectively.

\section{Variable selection}

We have given 140 variables for the calibration set. The data are presented in Figure 2. At the lower end, we see larger variation in the curves, while at higher end we see very small variation. We run GA for 140 variables using a
PC-ANN regression method of which the maximum number of factors allowed is the optimal number of components determined by cross-validation on the model containing all the variables, and we used the selected variables for the running of PC-ANN. The selected wavelengths are 244, 245, 246, 329, 330, 331, 332, 333, $334,335,345$ and $346 \mathrm{~nm}$ for $m$-nitroaniline and 224 , 225, 226, 227, 228, 229, 230, 231, 402, 403, 404, 407, 408,409 and $410 \mathrm{~nm}$ for o-nitroaniline and 228, 229, 230, $231,255,256$ and $257 \mathrm{~nm}$ for $p$-nitroaniline and is as shown in Figure 2. The present study shows that the GA can be a good method for feature selection in spectral data sets. The results obtained on data set of $m$ nitroaniline, $o$-nitroaniline and $p$-nitroaniline mixture demonstrate that the predictive ability of the models obtained with the wavelengths selected by the algorithm 
Table 6. Statistical parameters of the optimized matrix using GA-PC-ANN.

\begin{tabular}{lccc}
\hline & Training set & validation set & Prediction set \\
\hline $\boldsymbol{m}$-nitroaniline & & & \\
$\mathrm{R}^{2}$ & 0.9959 & 0.9826 & 0.9611 \\
$\mathrm{RMSE}$ & 0.3638 & 0.8525 & 0.7848 \\
$\mathrm{RSEP}(\%)$ & 3.7897 & 9.2517 & 10.796 \\
& & & \\
o-nitroaniline & & & \\
$\mathrm{R}^{2}$ & 0.9982 & 0.9874 & 0.9947 \\
$\mathrm{RMSE}$ & 0.1708 & 0.7745 & 0.2864 \\
RSEP (\%) & 2.5758 & 10.0156 & 4.4724 \\
& & & \\
$\boldsymbol{p}$-nitroaniline & & & \\
$\mathrm{R}^{2}$ & 0.9978 & 0.9862 & 0.9993 \\
RMSE & 0.2299 & 0.4283 & 0.1851 \\
RSEP (\%) & 2.6842 & 7.2632 & 1.8441 \\
\hline
\end{tabular}

is very often much better.

\section{Statistic parameters}

For the evaluation of the predictive ability of a multivariate calibration model, the root mean square error of prediction (RMSEP) and relative standard error of prediction (RSEP) can be used (Niazi et al., 2006):

$R M S E P=\sqrt{\frac{\sum_{i=1}^{n}\left(y_{\text {pred }}-y_{\text {obs }}\right)^{2}}{n}}$

$\operatorname{RSEP}(\%)=100 \times \sqrt{\frac{\sum_{i=1}^{n}\left(y_{\text {pred }}-y_{\text {obs }}\right)^{2}}{\sum_{i=1}^{n}\left(y_{\text {obs }}\right)^{2}}}$

where $y_{\text {pred }}$ is the predicted concentration in the sample,

$y_{o b s}$ is the observed value of the concentration in the sample and $n$ is the number of samples in the validation set. The RMSEP, RSEP and $\mathrm{R}^{2}$ results are summarized in Table 6.

\section{Determination of nitroaniline isomers in synthetic mixtures}

The predictive ability of method was determined using six three-component nitroaniline isomers mixtures (their compositions are given in Table 4). The results obtained by applying GA-PC-ANN algorithm to six synthetic samples are listed in Table 4. Also, Table 4 shows the recovery for prediction series of nitroaniline isomers mixtures. As can be seen, the recovery was also quite acceptable. The root mean square error of prediction and relative standard error of prediction results are summarized in Table 6 . The plots of the predicted concentration versus actual values are as shown in Figure 3 for nitroaniline isomers (line equations and $R^{2}$ values are also shown). The results in this figure show the prediction ability of this model for calculation of three nitroanilines concentrations.

\section{Conclusion}

A GA-PC-ANN calibration model was proposed for the simultaneous determination of $m$-nitroaniline, $\quad 0$ nitroaniline and $p$-nitroaniline. Modeling with ANNs is a more robust, simpler, practically applicable method, utilized for predicting the concentration of unknown samples than standard methods using calibration lines. Based on the results obtained in this work, application of GA-PC-ANN method, which was trained with the back propagation of errors learning algorithm can construct a powerful model for simultaneous determination of $m$ nitroaniline, $o$-nitroaniline and $p$-nitroaniline in an effective and accurate way. A GA-PC-ANN was used to build an efficient model for predicting concentrations of $m$ nitroaniline, $o$-nitroaniline and $p$-nitroaniline in mixed solutions. Non-linear effects resulting from analyteanalyte interaction in this system can be modeled by artificial neural network. There is no need to know the exact form of the analytical function on which the model should be built, also it requires no complex pretreatment 

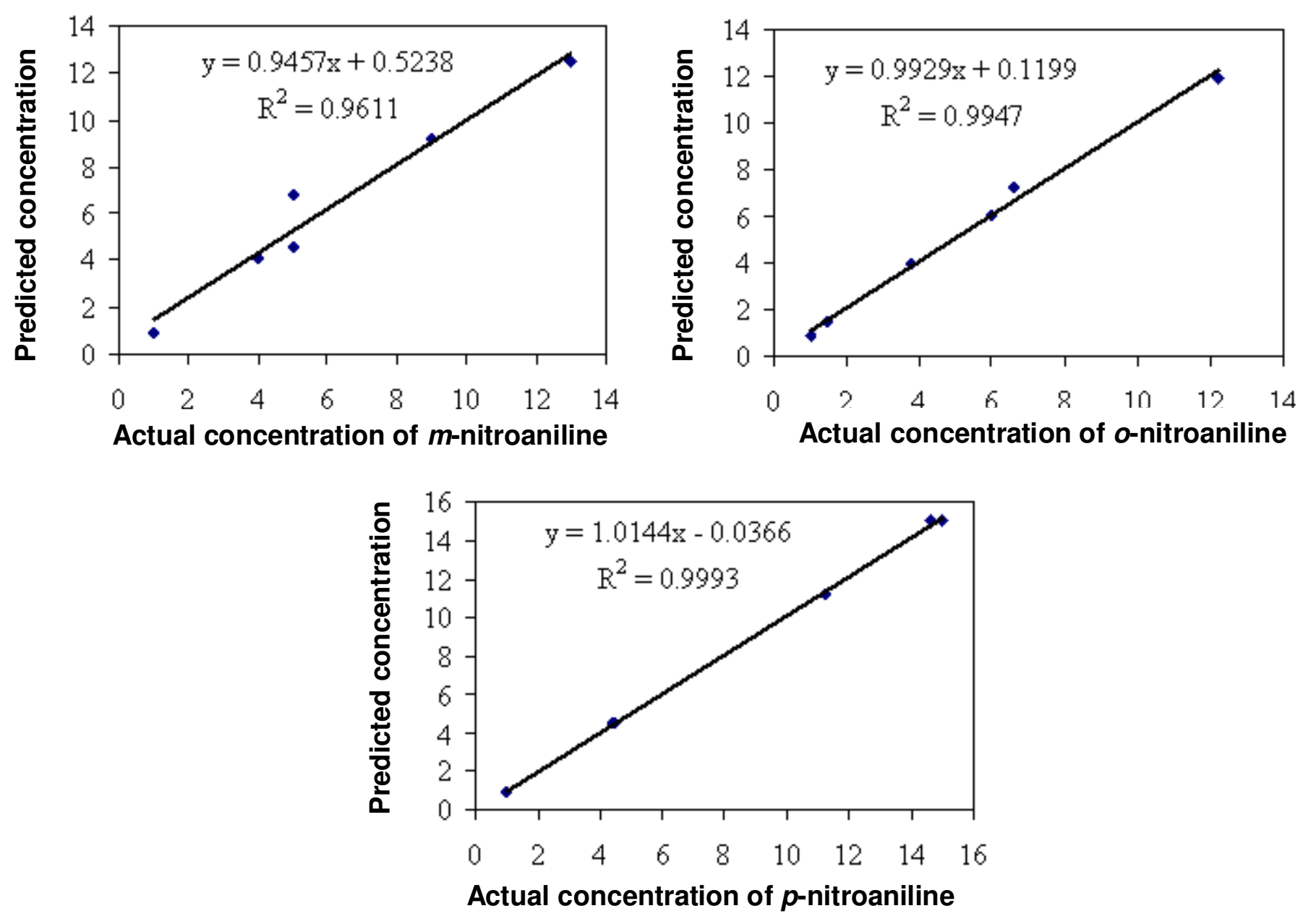

Figure 3. Plots of predicted concentration versus actual concentration for nitroaniline isomers by GA-PC-ANN Method. Concn: concentration.

of the samples containing analytes. This technique is simple, fast and affordable.

\section{REFERENCES}

Absalan G, Soleimani M (2004). Simultaneous Determination of Aniline and Cyclohexylamine by Principal Component Artificial Neural Networks. Anal. Sci., 20: 879-882.

Ai-Ghabsha TS, Rahim SA, Townshend A (1976), Spectrophotometric determination of microgram amounts of amines with chloranil. Anal. Chim. Acta., 85: 189-194.

Arcos MJ, Ortiz MC, Villahoz B, Sarabia LA (1997). Genetic-algorithmbased wavelength selection in multicomponent spectrometric determinations by PLS: application on indomethacin and acemethacin mixture. Anal. Chim. Acta., 339: 63-77.

Au Kuzmina NV, Kudasheva FK, Maistrenko NV, Sapelnikova SV (2003). Influence of the nature of the pasting liquid on the accumulation of nitroanilines at carbon paste electrode during determination by absorptive stripping voltammetry. Anal. Bioanal. Chem., 375: 1182-1185.

Balamurugan C, Aravindan C, Kannan K, Sathyanarayana D, Valliappan K, Manavalan R (2003). Artificial neural network for the simultaneous estimation of multicompnent sampled by UV spectrophotometry. Indian .J. Pharm. Sci., 65: 274-278.
Berzas Nevado JJ, Rodriguez Flores J, Castaneda Penalvo G (1997). Simultaneous spectrophotometric determination of ethinylestradiol and levonorgestrel by partial least squares and principal component regression multivariate calibration. Anal. Chim. Acta, 340: 257-265.

Bourquin J, Schmidli H, Van Hoogevest P, Leuenberger H (1997). Basic concepts of artificial neural networks (ANN) modeling in the application to pharmaceutical development. Pharm. Dev. Technol., 2: 95-109.

Depczynski U, Frost VJ, Molt K (2000). Genetic algorithms applied to the selection of factors in principal component regression. Anal. Chim. Acta., 420: 217-227.

Despagne F, Massart DL (1998). Neural networks in multivariate calibration. Analyst, 11: 57R-178R.

Faller C, Meyer A, Henze G (1996). Voltammetric determination of loxynil and 2-methyl-3-nitroaniline using $\mathrm{C}_{18}$ modified carbon paste electrodes. Fresenius J. Anal. Chem., 356: 279-283.

Farroha SM, Emeish SS (1975). Gas-chromatographic separation of aromatic amines, nitriles and hydrocarbons. Talanta, 22: 121-128.

Fausett L (1994). Fundamentals of Neural Networks: Architectures,Algorithms and Applications. Printice-Hall: New Jersey, Chapter 1 and 6.

García-Reiriz A, Damiani PC, Olivieri AC (2007). Analysis of amoxicillin in human urine by photo-activated generation of fluorescence excitation-emission matrices and artificial neural networks combined with residual bilinearization. Anal. Chim. Acta., 588: 192-199.

Ghasemi J, Niazi A (2007). Spectrophotometric simultaneous 
determination of nitroaniline isomers by orthogonal signal correctionpartial least squares.Talanta, 65: 1168-1173.

Goodarzi M, Goodarzi T, Ghasemi N (2007). Spectrophotometric Simultaneous Determination of Manganese (II) and Iron(II) in Pharmaceutical by Orthogonal Signal Correction-Partial Least Squares. Ann. Chim., 97: 303-312.

Grabaric Z, Grabaric B, Esteban M, Casassas E (1997). Resolution of global signals using ratio differential pulse polarograms: Determination of $\mathrm{p}$-nitroaniline and $\mathrm{p}$-nitrotoluene in their mixture. $\mathrm{J}$. Electroanal. Chem., 420: 227-234.

Gurten AA, Cuan M, Abdullah MI, Ayar A (2006). Effect of the temperature and mobile phase composition on the retention behavior of nitroanilines on ligand-exchange stationary phase. J. Hazard. Mater., B, 135: 53-57.

Hagan MT, Menhaj MB (1994). Training feedforward networks with the Marquardt algorithm, IEEE., Trans. Neur. Networks, 6: 989-993.

Hibbert DB (1993). Genetic algorithms in chemistry Chemometrics. Intell. Lab. Syst., 19: 277-293.

Isaeva B, Kilimnik A, Isaeva O (1991). Polarographic determination of ortho-nitroaniline using a copper-amalgam electrode. Ind. Lab., 57: 1011.

Jalali-Heravi M, Masoum S, Shahbazikhah $\mathrm{P}$ (2004). Simulation of ${ }^{13} \mathrm{C}$ nuclear magnetic resonance spectra of lignin compounds using principal component analysis and artificial neural networks. J. Mag. Reson., 171: 176-185.

Kalivas JH (2001). Basis sets for multivariate regression. Anal. Chim. Acta., 428: 31-40.

Leardi R (1994). Application of a genetic algorithm to feature selection under full validation conditions and to outlier detection. J. Chemometrics, 8: 65-79.

Leardi R (1996). in: J. Devillers (Ed.), Genetic Algorithms in Feature Selection. In Genetic Algorithms in Molecular Modelling. Academic Press, London, p. 67.

Leardi R (2000). Application of genetic algorithm-PLS for feature selection in spectral data sets. J. Chemometrics, 14: 643-655.

Leardi R (2007). Genetic algorithms in chemistry. J. Chromatogr. A, 1158: 226-233.

Leardi R, Boggia R, Terrile M (1992). Genetic algorithms as a strategy for feature selection. J. Chemometrics, 6: 267-281.

Leardi R, Gonzalez AL (1998). Genetic algorithms applied to feature selection in PLS regression: how and when to use them Chemometrics. Intell. Lab. Syst., 41: 195-207.

Leardi R, Seasholtz MB, Pell RJ (2002). Variable selection for multivariate calibration using a genetic algorithm: prediction of additive concentrations in polymer films from Fourier transforminfrared spectral data. Anal. Chim. Acta., 461: 189-200.

Lopez-Aviia V, Northcutt R (1981). Pittsburgh Conference on Analytical Chemistry and Applied Spectroscopy, Abstract No. 224.

Lucasius CB, Kateman G (1993). Understanding and using genetic algorithms Part 1. Concepts, properties and context Chemometrics. Intell. Lab. Syst., 19: 1-33.

Lurie JJ (1978). Handbook of Analytical Chemistry. Mir Publishers, Moscow, p. 3

Marbach R, Heise HM (1990). Calibration modeling by partial leastsquares and principal component regression and its optimization using an improved leverage correction for prediction testing Chemom. Intell. Lab. Syst., 9: 45-63.

Niazi A, Yazdanipour A, Goodarzi M, Kamkar HR, Rafinejad A (2006). Spectrophotometric Simultaneous Determination of Zinc, Manganese and Iron in Pharmaceutical Preparations Using OSC-PLS. Chin. Chem. Lett., 17: 1347-1350.

Ni Y, Liu C, Kokot S (2000). Simultaneous kinetic spectrophotometric determination of acetaminophen and phenobarbital by artificial neural networks and partial least squares. Anal. Chim. Acta., 419: 185-196.

Pan Y, Jiang J, Wang Z (2007). Quantitative structure-property relationship studies for predicting flash points of alkanes using group bond contribution method with back-propagation neural network. J. Hazard. Mater., 147: 424-430.
Rahim SA, Ismail ND, Bashir WA (1987). Spectrophotometric determination of aniline in aqueous solution by azo-dye formation with diazotized p-nitroaniline. Microchimica Acta., 90: 417-423.

Revanasiddappa HD, Kumar K, Bilwa M (2001). A Facile Spectrophotometric Determination of Nitrite Using Diazotization with p-Nitroaniline and Coupling with Acetyl Acetone. Microchimica. Acta., 137: 249-253.

Rumelhart DE, McClelland JL (1986). Parallel Distributed Processesing: Explorations in the Microstructure of Cognition. MIT Press: Cambridge, MA, Chapter 1.

Salari D, Daneshvar N, Aghazadeh F, Khataee AR (2005). Application of artificial neural networks for modeling of the treatment of wastewater contaminated with methyl tert-butyl ether (MTBE) by UV/ $\mathrm{H}_{2} \mathrm{O}_{2}$ process, J. Hazard. Mater., 125: 205-210.

Sathyanarayana D, Kannan K, Manavalan R (2004). Back-propagation neural network Model for simultaneous spectrophotometric estimation of losartan potassium and hydrochlorothiazide in tablet dosage. Indian J. Pharm. Sci., 66: 745-752.

Schalkoff RJ (1997). Artificial Neural Networks, McGraw-Hill:New York, 1-3: 6,7.

Scher AL, Adamo NC (1993). Liquid chromatographic determination of 2-chloro-4-nitroaniline, 2-naphthol, and 2,4-dinitroaniline in D\&C Red No.36. J. AOAC Int., 76: 287-291.

Tang L, Zeng GM, Shen GL, Zhang Y, Huang GH, Li JB (2006). Simultaneous amperometric determination of lignin peroxidase and manganese peroxidase activities in compost bioremediation using artificial neural networks. Anal. Chim. Acta., 579: 109-116.

Wolff G, Nürnberg HW (1966). Anwendungen der Pulse-Polarographie in der organischen Analyse. Fresenius J. Anal. Chem., 216: 169-183.

Wythoff BJ (1993). Backpropagation neural networks A tutorial. Chemom. Intell. Lab. Syst., 18: 115-155.

Yin C, Shen Y, Liu S, Yin Q, Guo W, Pan Z (2001). Simultaneous quantitative UV spectrophotometric determination of multicomponents of amino acids using linear neural network. Comput. Chem., 25: 239-243.

Zhang YX (2007). Artificial neural networks based on principal component analysis input selection for clinical pattern recognition analysis. Talanta, 73: 68-75.

Zhang Y, Li H, Hou A, Havel J (2005). Artificial neural networks based on genetic input selection for quantification in overlapped capillary electrophoresis peaks. Talanta, 65: 118-128.

Zupan J, Gasteiger J (1991). Neural networks: anew method for solving chemical problems or just a passing phase. Anal. Chim. Acta., 248: 1-30.

Zupan J, Gasteiger J (1999). Neural Networks in Chemistry and Drug Design. Wiley-VCH: New York, Chapter 1.

Zupan J, Novic M, Ruisanchez I (1997). Kohonen and counterpropagation artificial neural networks in analytical chemistry. Chemom. Intell. Lab. Syst., 38: 1-23. 